\title{
Pseudomonas sp. LZ-Q continuously degrades phenanthrene under hypersaline and hyperalkaline condition in a membrane bioreactor system
}

\author{
Yiming Jiang ${ }^{1}$, Haiying Huang ${ }^{1}$, Mengru $\mathrm{Wu}^{2}$, Xuan $\mathrm{Yu}^{1}$, Yong Chen ${ }^{1}, \mathrm{Pu} \mathrm{Liu}^{3}$, Xiangkai $\mathrm{Li}^{1}$ \\ ${ }^{1}$ Ministry of Education Key Laboratory of Cell Activities and Stress Adaptations, School of Life Science, Lanzhou \\ University, Lanzhou 730000, China \\ ${ }^{2}$ State Key Laboratory of Microbial Resources, Institute of Microbiology, Chinese Academy of Sciences, \\ Beijing 100101, China \\ 3 Department of Development Biology Sciences, School of Life Science, Lanzhou University, Lanzhou 730000, China
}

Received: 13 July 2015 / Accepted: 17 December 2015 / Published online: 17 March 2016

\section{Graphical Abstract}

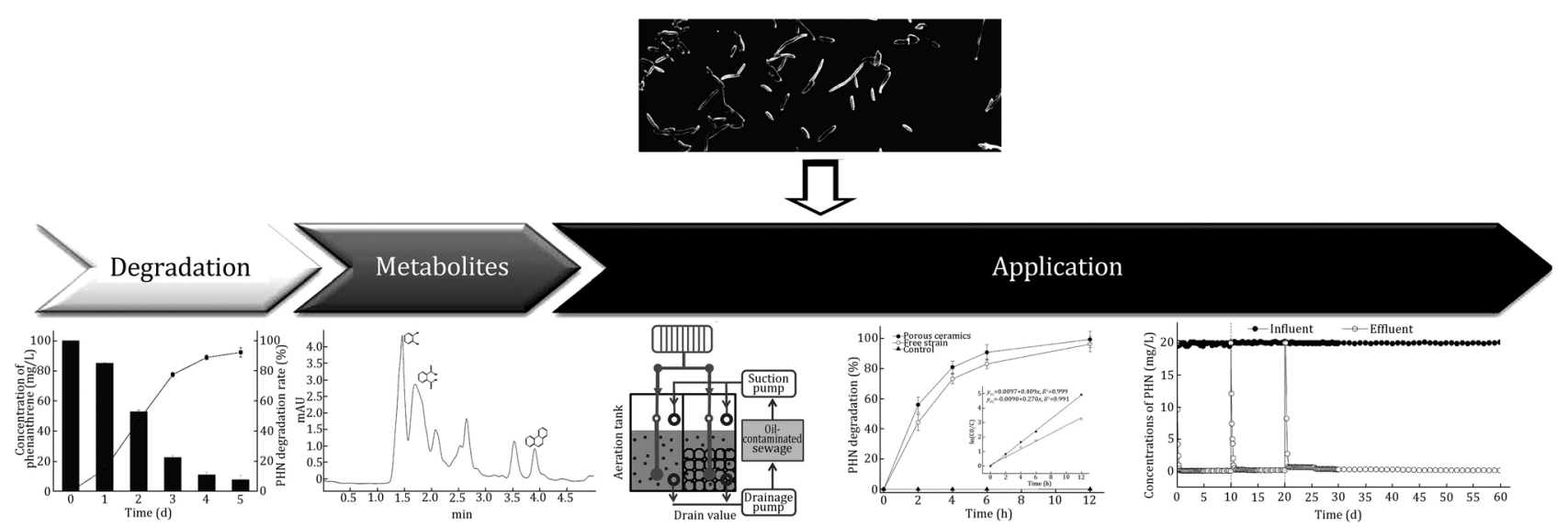

\begin{abstract}
Phenanthrene is one of the most recalcitrant components of crude oil-contaminated wastewater. An efficient phenanthrene-degrading bacterium Pseudomonas sp. strain named LZ-Q was isolated from oil-contaminated soil near the sewage outlet of a petrochemical company. Pseudomonas sp. LZ-Q is able to degrade $1000 \mathrm{mg} / \mathrm{L}$ phenanthrene in Bushnell-Hass mineral salt medium. It also degrades other polycyclic aromatic hydrocarbons such as naphthalene, anthracene, pyrene, petrol, and diesel at broad ranges of
\end{abstract}

Yiming Jiang, Haiying Huang and Mengru Wu contributed equally to this work.

$\triangle$ Correspondence: xkli@lzu.edu.cn (X. Li) salinities of $5 \mathrm{~g} / \mathrm{L}$ to $75 \mathrm{~g} / \mathrm{L}$, pHs of $5.0-10.0$, and temperatures of $10-42{ }^{\circ} \mathrm{C}$. Therefore, Pseudomonas sp. LZ-Q could be a good candidate for remediation of polycyclic aromatic hydrocarbon (PAH)-contaminated wastewater. A membrane bioreactor (MBR) was applied to investigate the remediation ability of the strain LZ-Q. Wastewater containing phenanthrene with $\mathrm{pH}$ of 8 , salinity of $35 \mathrm{~g} / \mathrm{L}$, and COD of $500 \mathrm{mg} / \mathrm{L}$ was continuously added to the system (HRT $=3 \mathrm{~h}$ ). Results showed that Pseudomonas sp. LZ-Q is capable of degrading $96 \%$ of $20 \mathrm{mg} / \mathrm{L}$ phenanthrene and $94 \%$ of $500 \mathrm{mg} / \mathrm{L} \mathrm{COD}$ for 60 days in a continuous mode. These results showed that the MBR system with strain LZ-Q might be a good approach for PAHs' remediation in industrial wastewaters. 
Keywords Pseudomonas sp. LZ-Q, Phenanthrene degradation, Immobilization microorganisms, Hypersaline and hyperalkaline wastewater, Membrane bioreactor (MBR)

\section{INTRODUCTION}

Nowadays, water pollution is becoming an increasingly concerned environmental problem (Schwarzenbach et al. 2010). In the northwest of China, water pollution events occur frequently. Among the refractory organics causing water pollution events, polycyclic aromatic hydrocarbons (PAHs) are considered to be the most environmentally significant and hazardous to human health (Wang et al. 2013). PAHs are a group of organic chemicals consisting of two or more fused benzene rings that are in linear, angular, and cluster arrangements (Bamforth and Singleton 2005). Most of the PAHs are toxic, mutagenic, carcinogenic, and recalcitrant $(\mathrm{Wu}$ et al. 2010; Patel et al. 2012). PAHs released into the environment would cause serious risks to natural environment, fishery, agriculture and human health (Wang et al. 2013). Therefore, controlling PAHs pollution is an urgent task in water protection.

Phenanthrene (PHN) identified as one of the priority pollutants is a typical PAH and some of its derivatives are carcinogenic (Jerina et al. 2012). Microbes are able to degrade PHN and provide an ideal bioremediation approach. For example, Pseudomonas stutzeri ZP2 can degrade more than $90 \%$ of PHN at 1000 ppm in 6 days (Zhao et al. 2009). Pseudomonas sp. JM2 isolated from active sewage sludge of a chemical plant removes $50 \mathrm{mg} / \mathrm{L}$ PHN within 4 days (Ma et al. 2012). However, successful applications of using microbes to remediate PHN in industrial wastewater are still scarce (Lefebvre and Moletta 2006). Industrial wastewater with wide ranges of $\mathrm{pHs}$ and hypersalinities inhibits microbial respiration rates, reduces enzymes' activity, and elevates osmotic pressure of cells. Many of the known PHN-degrading bacteria cannot survive well under such condition and function properly (Kunst and Rapoport 1995; Metcalf 2003). Therefore, searching for a PHN degrading strain with survival ability in industrial wastewater is critical for applications of PHN's remediation.

Membrane bioreactor (MBR) is proven to be a good method for wastewater treatment and attracts extensive attentions, because MBR is characterized with high pollutant removal efficiency. Removal of PAHs by MBR has been studied (González et al. 2012). However, membrane fouling is one significant limitation when using MBR to treat wastewater (Tang et al. 2010; Zhang et al. 2011). Previous studies have demonstrated that microorganism immobilization technology (MIT) can improve the effectiveness of sewage treatment and enable cells to separate from aqueous solution easily and reduce the membrane fouling. MIT has been widely applied in industrial operation and works efficiently (Juang et al. 2008; Bai et al. 2009; Ting and Sun 2000; Yan and Viraraghavan 2001). Immobilizing microbiota B500 on macro-porous carriers enhances the removal efficiency for contaminants in wastewater (Park et al. 2005). Iron-oxidizing bacteria immobilized onto polyurethane foam decrease the risk of membrane fouling and increase the efficiency of pollutants' degradation (Zhou et al. 2008).

In this study, a bacterial strain LZ-Q utilizing PHN as the sole carbon source was isolated from petroleumcontaminated soil. Ceramics are used as carriers of strain LZ-Q in MBR system. Strain LZ-Q degraded PHN efficiently and this MBR with immobilized strain LZ-Q cells showed ability of degradation of PHN in artificial petrochemical wastewater in long period.

\section{RESULTS AND DISCUSSION}

\section{Isolation and characterizations of strain LZ-Q}

Four bacterial strains with the ability of phenanthrene degradation were isolated from petrochemicalcontaminated soils in Lanzhou reach of the Yellow River, China. All four strains were gram-negative and aerobic. By comparison of 16S rRNA gene sequences, LZ-Q (GenBank No.: KR140091, CCTCC No.: M2015564), LZ-O (GenBank No.: KR140089), and LZ-G (GenBank No.: KR140088) were closely related to Pseudomonas spp. and LZ-P (GenBank No.: KR140090) was related to Rhizobium sp. Growths of the isolated strains using phenanthrene $(1000 \mathrm{mg} / \mathrm{L})$ as the sole carbon source were determined at $\mathrm{pH} 7,180 \mathrm{r} / \mathrm{min}$, and $28^{\circ} \mathrm{C}$. All isolated strains can grow under such condition and strain LZ-Q reached highest optical density $\left(O D_{600 \mathrm{~nm}}\right)$ of 0.25 after $168 \mathrm{~h}$ incubation (Fig. 1A). This result suggests that all four strains can degrade PHN, and strain LZ-Q was chosen for further study as it showed higher growth when using PHN as sole carbon source. The strain LZ-Q was short rod-shaped bacterium. The colonies of strain LZ$\mathrm{Q}$ were mostly small, opaque, circular or irregular ovalshaped and oyster white-colored with moist and luster surface. ViTek phenotype analysis showed that strain LZ-Q 
Fig. 1 A Growth curves of isolated strains and E. coli. B Phylogenetic tree based on 16S rRNA gene sequence showing the relationship between corresponding sequences of the genus Pseudomonas genus
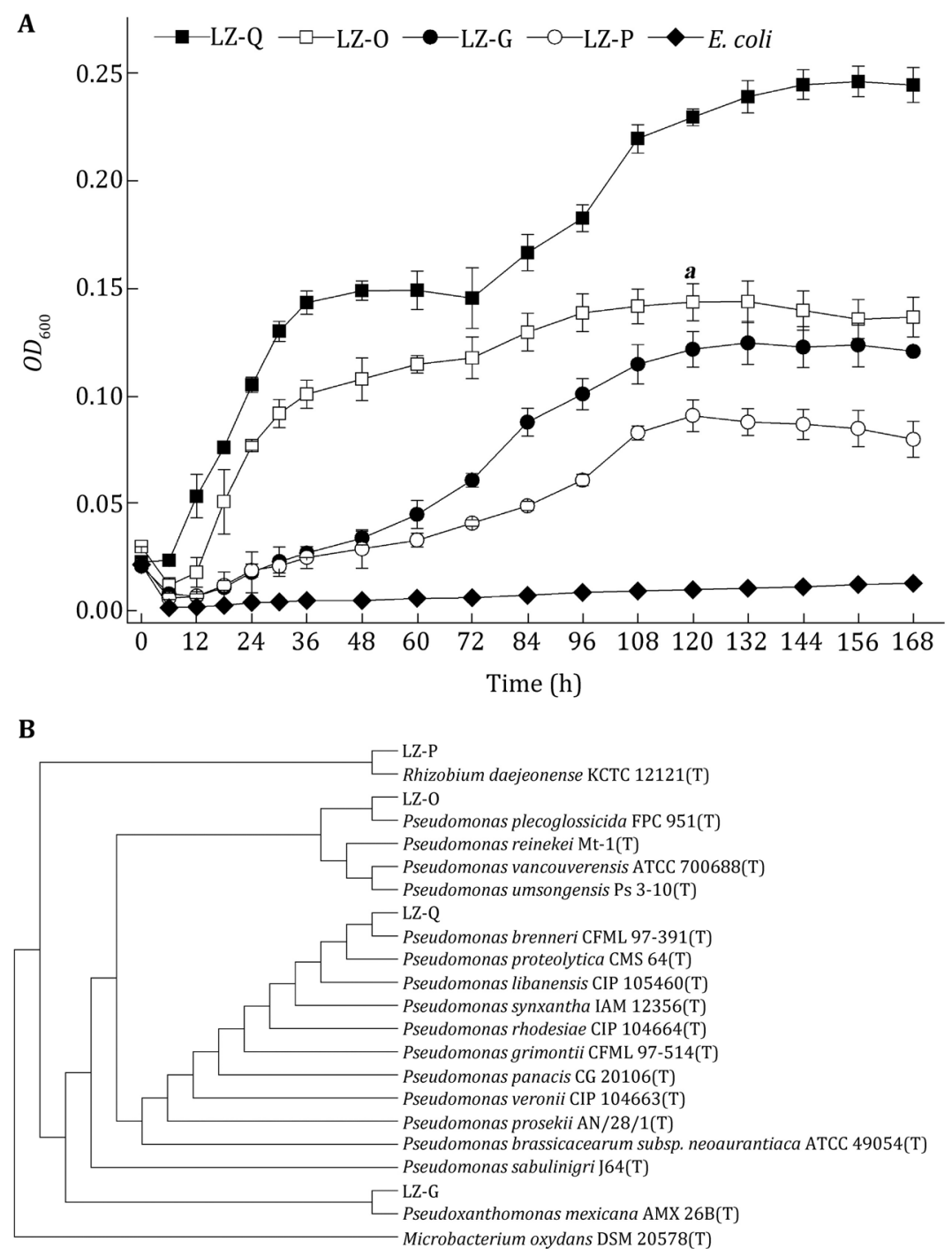

was 95\% closely related to Pseudomonas fluorescens (Table 1). A phylogenetic tree based on neighbor-joining algorithm demonstrated that LZ-Q clustered with $P$. brenneri, which falls within the $P$. fluorescens group, at a bootstrap value of $75 \%$ (Fig. 1B). Our data also showed that strain LZ-Q degrades various PAHs, petrol, and diesel, suggesting it might be an ideal strain for $\mathrm{PAH}$ bioremediation (Table 1).

Table 1 ViTek report of strain LZ-Q

Biochemical details

\begin{tabular}{llllllllllllllllll}
\hline 2 & APPA $^{-}$ & - & 3 & ADO & - & 4 & PyrA & + & 5 & IARL & - & 7 & dCEL & - & 9 & BGAL & - \\
10 & $\mathrm{H}_{2} \mathrm{~S}$ & - & 11 & BNAG & - & 12 & AGLTp & - & 13 & dGLU & + & 14 & GGT & - & 15 & OFF & - \\
17 & BGLU & - & 18 & dMAL & - & 19 & dMAN & - & 20 & dMNE & + & 21 & BXYL & - & 22 & BAlap & - \\
23 & ProA $^{-}$ & + & 26 & LIP & - & 27 & PLE & - & 29 & TyrA & + & 31 & URE & - & 32 & dSOR & - \\
33 & SAC- & - & 34 & dTAG & - & 35 & dTRE & + & 36 & CIT & + & 37 & MNT & - & 39 & 5 KG & - \\
40 & ILATk- & - & 41 & AGLU & - & 42 & SUCT & + & 43 & NAGA & - & 44 & AGAL & - & 45 & PHOS & - \\
46 & GlyA- & - & 47 & ODC & - & 48 & LDC & - & 53 & IHISa & - & 56 & CMT & - & 57 & BGUR & - \\
58 & O129R & + & 59 & GGAA & - & 61 & IML & + & 62 & ELLM & - & 64 & lLATa & - & & &
\end{tabular}

"+" and "-" represent whether the strain can utilize the substrate or not 


\section{Characterization of phenanthrene degradation in strain LZ-Q}

In order to determine the optimum degradation condition, strain LZ-Q was cultivated in BH medium with $100 \mathrm{mg} / \mathrm{L}$ PHN under pHs ranging from 5 to 10 and temperatures varying from $10{ }^{\circ} \mathrm{C}$ to $42{ }^{\circ} \mathrm{C}$. Highest $O D_{600 \mathrm{~nm}}$ was achieved at $\mathrm{pH} 7.0$ and $28{ }^{\circ} \mathrm{C}$, which indicates that the optimum growth and PHN degrading condition for strain LZ-Q is at $\mathrm{pH} 7.0$ and $28{ }^{\circ} \mathrm{C}$ (Fig. 2A, B). Under the optimum growth condition, strain LZ-Q degraded $92.27 \%$ PHN after 5 days cultivation (Fig. 2C).

Studies about Pseudomonas spp. which can degrade phenanthrene have been reported previously. Bacterial strain $P$. sp. Ph6-gfp isolated from clover grown in a PAH-contaminated site showed a $81.1 \%$ decrease of phenanthrene $(50 \mathrm{mg} / \mathrm{L})$ within 15 days (Sun et al. 2014), and strain $P$. stutzeri ZP2 isolated from soil in oil refinery fields in Shanghai China could reduce about 96\% PHN (250 mg/L) within 6 days (Janbandhu and Fulekar 2011). In line with previous studies, strain LZ-Q that is closely related to Pseudomonas genus can utilize a range extension of refractory organics and degrade high concentrations of phenanthrene (Lin et al. 2014). The degradation rate is higher than $P$. sp. but lower than P. stutzeri ZP2 (Zhao et al. 2009; Sun et al. 2014). In addition, the results also showed that strain LZ-Q can grow at $\mathrm{pHs}$ of 5.0-10.0 and temperatures ranging from $10{ }^{\circ} \mathrm{C}$ to $42{ }^{\circ} \mathrm{C}$, suggesting that it was capable of degrading PHN using phenanthrene as the sole carbon source at broad pHs and temperatures. Therefore, even though the degradation rate of PHN is not the most efficient, strain LZ-Q could degrade PHN more efficiently as the bio-mediation condition in wastewater treatment plant is variable.

Degradation of PHN is often affected by the high salinity (Haritash and Kaushik 2009). To further determine the influence of high salinity on growth and PHN degradation of strain LZ- $Q$, the adaptability to salinity was investigated in $\mathrm{BH}$ medium with the addition of different concentrations of $\mathrm{NaCl}(5,10,35,40,50,75$ and $100 \mathrm{~g} / \mathrm{L}$ ) after $120 \mathrm{~h}$ of incubation. Strain LZ-Q degraded PHN with $5 \mathrm{~g} / \mathrm{L}$ to $75 \mathrm{~g} / \mathrm{L} \mathrm{NaCl}$ (Fig. 3A). These results showed that strain LZ-Q could degrade PHN efficiently under hypersaline condition. As the high salinity of industrial wastewater usually restricts microorganisms to remove pollutants, studies about bacterial strains which degraded PHN under hypersaline condition and were used in industrial wastewater plant were limited (Kunst and Rapoport 1995; Metcalf 2003). P. sp. BZ-3 degraded $75 \%$ phenanthrene under the $20 \mathrm{~g} / \mathrm{L} \mathrm{NaCl}$ (Lin et al. 2014). Our data showed that strain LZ-Q also remove phenanthrene contaminants
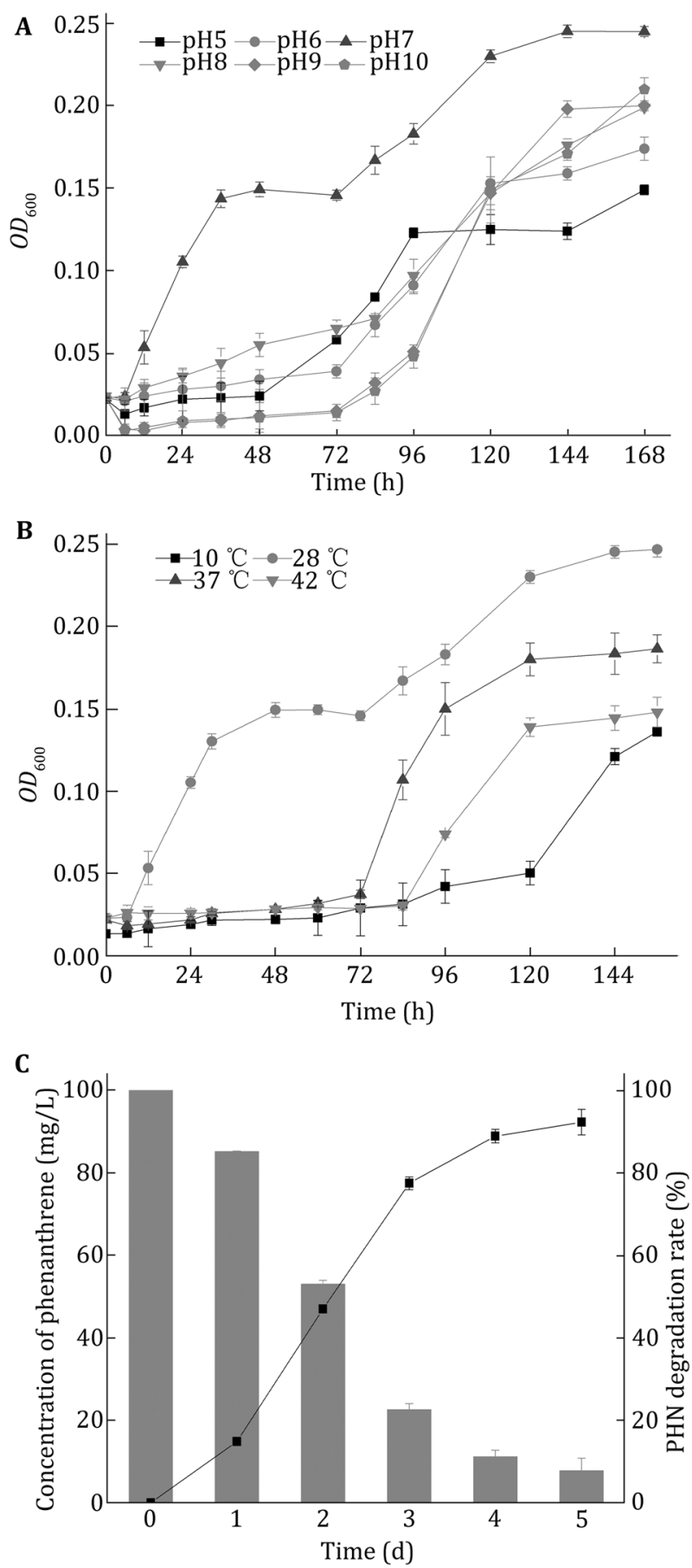

Fig. 2 A Optimum $\mathrm{pH}$ conditions of strain LZ-Q. B Optimum temperature conditions of strain LZ-Q. C Biodegradation rate of PHN under optimum conditions

under high salinity $(75 \mathrm{~g} / \mathrm{L} \mathrm{NaCl})$ and high alkalinity (pH 9) conditions efficiently. Results showed that LZ-Q's PHN degradation ability which is $3 \%$ lower than $P$. stutzeri ZP2, is not the highest at optimum conditions. But it can degrade PHN at pHs and temperatures which other strains cannot, suggesting that strain LZ-Q is a potential strain for application. 
Fig. 3 A $O D_{600}$ and $P H N$

degradation rate of LZ-Q

under saline condition. B The

antibiotic resistance of strain

LZ-Q
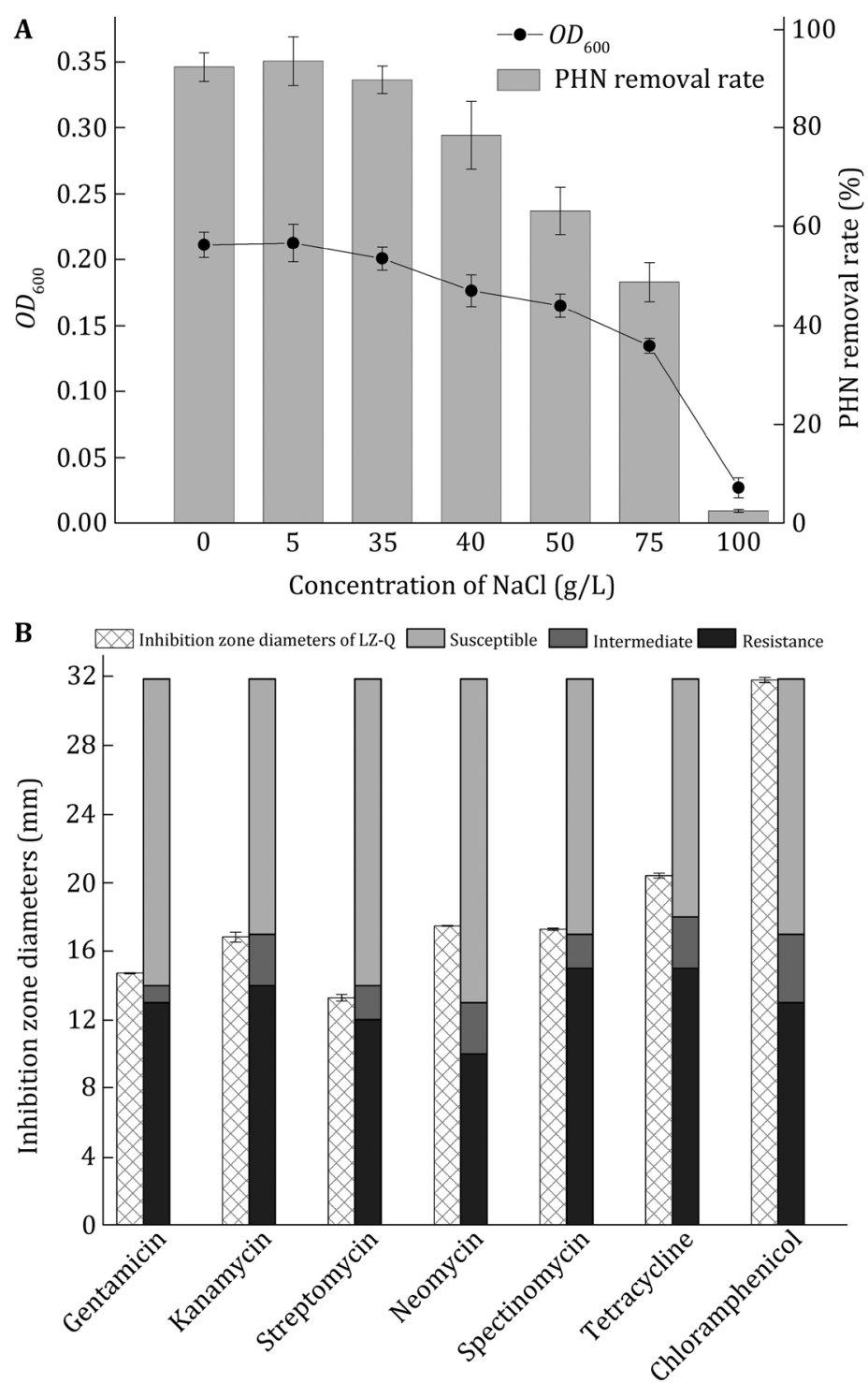

Previous studies proposed that multi-drug-resistant strains have a higher risk of spreading antibiotic resistance genes to indigenous flora (Masakorala et al. 2013). The antibiotic sensitive tests showed strain LZ-Q was sensitive to gentamicin, neomycin, spectinomycin, tetracycline, chloramphenicol, and intermediately susceptible to streptomycin and kanamycin (Fig. 3B). These results demonstrate that strain LZ-Q displays a profile of low resistance to antibiotics. Thus, $P$. sp. LZ-Q could be a suitable bioremediation additive in in situ wastewater treatment.

All the results provide the evidence that $P$. sp. LZ-Q might be a good potential candidate for the bioremediation of phenanthrene-contaminated industrial sewage under hypersaline and hyperalkaline conditions.

\section{Metabolic pathways of phenanthrene degradation by strain LZ-Q}

Two metabolic pathways including salicylic acid pathway and phthalic acid pathway were reported to degrade phenanthrene by bacteria (Prabhu and Phale 2003). Salicylic acid and catechol are intermediates of the salicylic acid pathway, phthalic acid is generated in the phthalic acid pathway (Peng et al. 2008; Haritash and Kaushik 2009). Strain LZ-Q utilizes salicylic acid, catechol, and phthalic acid as carbon sources (Table 2), suggesting that strain LZ-Q degrades phenanthrene through both salicylic acid pathway and phthalic acid pathway. The possible pathways for PHN degradation by strain LZ-Q are elucidated via HPLC method in this study. HPLC analysis data showed that peaks of 
Table 2 The diversity of degradable substrates by strain LZ-Q

\begin{tabular}{llll}
\hline Substrates & Growth situations & Substrates & Growth situations \\
\hline Phenanthrene & ++ & Diesel & ++ \\
Naphthalene & ++ & Salicylic acid & + \\
Anthracene & ++ & Phthalic acid & ++ \\
Pyrene & ++ & Diphenylamine & + \\
Petrol & + & & \\
\hline
\end{tabular}

+: Moderate, ++ : good

phthalic acid, catechol, and phenanthrene appeared at a retention time of $1.65,1.47$, and $3.91 \mathrm{~min}$, respectively (Fig. 4A, 4B, and 4C). After three-day cultivation of strain LZ-Q in BH/PHN, the peak at 3.91 min decreased and two main peaks occurred at 1.65 and $1.47 \mathrm{~min}$ (Fig. 4D), suggesting that phthalic acid and catechol

A
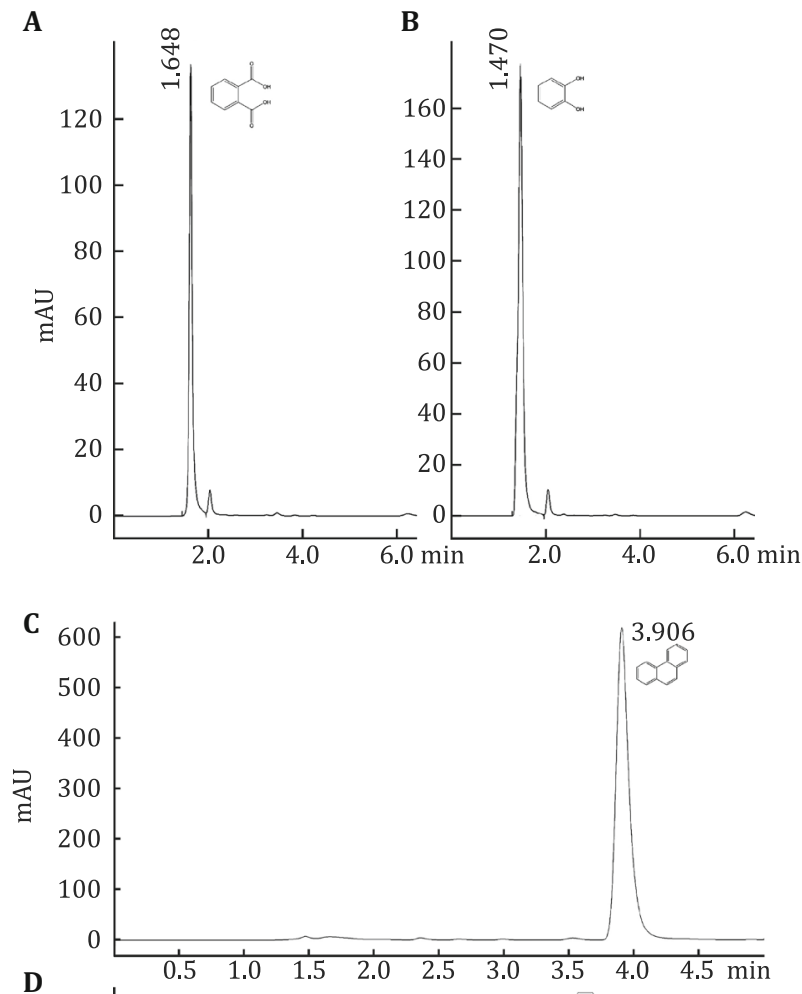

D

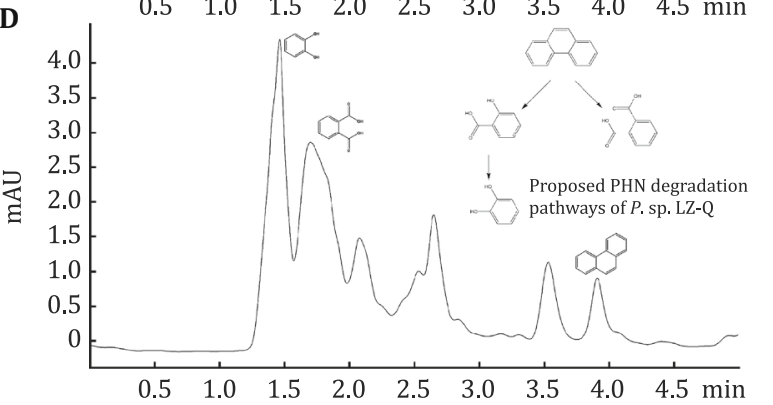

Fig. 4 Metabolite analysis using HPLC. Standard substances of phthalic acid (A), catechol (B) and phenanthrene (C); D Metabolite analysis were generated which is consistent with the previous result that strain LZ-Q could degrade salicylic acid, catechol, and phthalic acid. These results revealed that there are two PHN possible degradation pathways for LZ-Q (inset of Fig. 4D).

Studies of metabolic variations of phenanthrene biodegradation have been proved by HPLC method, such as studies of Pseudomonas putida NCIB 9816, Mycobacterium sp., and Burkholderia sp. strain BC1 (Boldrin et al. 1993; Yang et al. 1994; Chowdhury et al. 2014). Among Pseudomonas genus, studies about metabolic pathways of phenanthrene degradation showed a variation. Pseudomonas strain BZ-3 degraded PHN through salicylic acid pathway (Lin et al. 2014). According to the HPLC result, dimethylphthalate was detected as the intermediate product during PHN degradation. Therefore, Pseudomonas sp. USTB-RU biodegrade PHN via the phthalic acid pathway (Masakorala et al. 2013). In this study, strain LZ-Q degraded PHN both via salicylic acid pathway and phthalic acid pathway. This result is in agreement with the previous work revealing that Pseudomonas sp. N7 can degrade PHN via both pathways (Jia et al. 2008).

\section{Immobilized strain LZ-Q in MBR degrades PHN continuously and efficiently under hypersaline and hyperalkaline conditions}

Our previous results suggest that LZ-Q is suitable for application in hypersaline and hyperalkaline wastewater treatment. An MBR system was setup to test LZ-Q's ability to degrade PHN in wastewater. In our study, ceramics are used as adsorbing carriers. Results show that strain LZ-Q grew well on the surface and in the ostioles of ceramics. In order to determine the degradation ability of strain LZ-Q in MBR, microorganisms were treated with synthetic wastewater with $20 \mathrm{mg} / \mathrm{L}$ phenanthrene (pH 8 and $35 \mathrm{~g} / \mathrm{L} \mathrm{NaCl}$ ). The PHN degradation and COD removal were detected in free-bacteria reactors (FBR) and immobilizedmicroorganisms reactors (IMR). Decomposition rates of COD and PHN were faster in IMRs than in FBRs. The PHN degradation rate reached $90.68 \%$ in IMRs at $6 \mathrm{~h}$, 
while it was only $82.04 \%$ in FBRs with no significant differences $(P>0.05)$. A COD removal rate of $90.4 \%$ was achieved when using ceramics as carriers, whereas it was only $78.6 \%$ by free strain (Fig. 5). COD removal rate in IMRs had significant difference as compared with that in FBRs $(P<0.05)$. These results reveal that ceramic carriers with strain LZ-Q spur COD removal, suggesting that immobilized technique is suitable for wastewater treatment and similar to report about immobilizing bacteria onto ceramic carriers could remove COD more efficiently during operation (Kariminiaae-Hamedaani et al. 2003). Parameswarappa reported that ceramic material was a good choice for wastewater treatment and immobilization technology enhanced the degrading efficiency of ethylbenzene by Pseudomonas fluorescens-CS2 (Parameswarappa et al. 2008). In the batch and semi-continuous treatments, ceramics with immobilized consortia could remove COD, phosphate, nitrate, and $\mathrm{H}_{2} \mathrm{~S}$ effectively with removal rates of $89 \%, 77 \%, 99 \%$, and $99.8 \%$ for 1 month (Nagadomi et al. 2000). In a packed bed bioreactor, 82\% of the influent COD was removed within 160 days of operation (Kariminiaae-Hamedaani et al. 2003).

In addition, degradation of PHN in both FBRs and IMRs fitted to the exponential function and followed a pseudo-first-order kinetic model with rate constants of $0.372 / \mathrm{h} \quad\left(R^{2}=0.999\right) \quad$ and $\quad 0.290 / \mathrm{h} \quad\left(R^{2}=0.991\right)$, respectively (inset of Fig. 5A), and agrees with previous studies on PAHs biodegradation, such as Pseudomonas aeruginosa strain PAH-1 whose PHN degradation characteristics fitted to pseudo-first-order kinetic model (Ma et al. 2011).

The MBRs were operated at $19-21{ }^{\circ} \mathrm{C}$ with a HRT of $3 \mathrm{~h}$, and influent COD and PHN concentrations were maintained to 500 and $20 \mathrm{mg} / \mathrm{L}$, respectively. Based on different pHs (8, 9 and 10) of influent, process was divided into three phases. In the first phase, the effluent concentrations of COD and PHN were reduced to 26 and
Fig. 5 PHN degradation curve (A) and COD removal rate curve (B) of strain LZ-Q using in MBR. Reactor without strains was used as a control
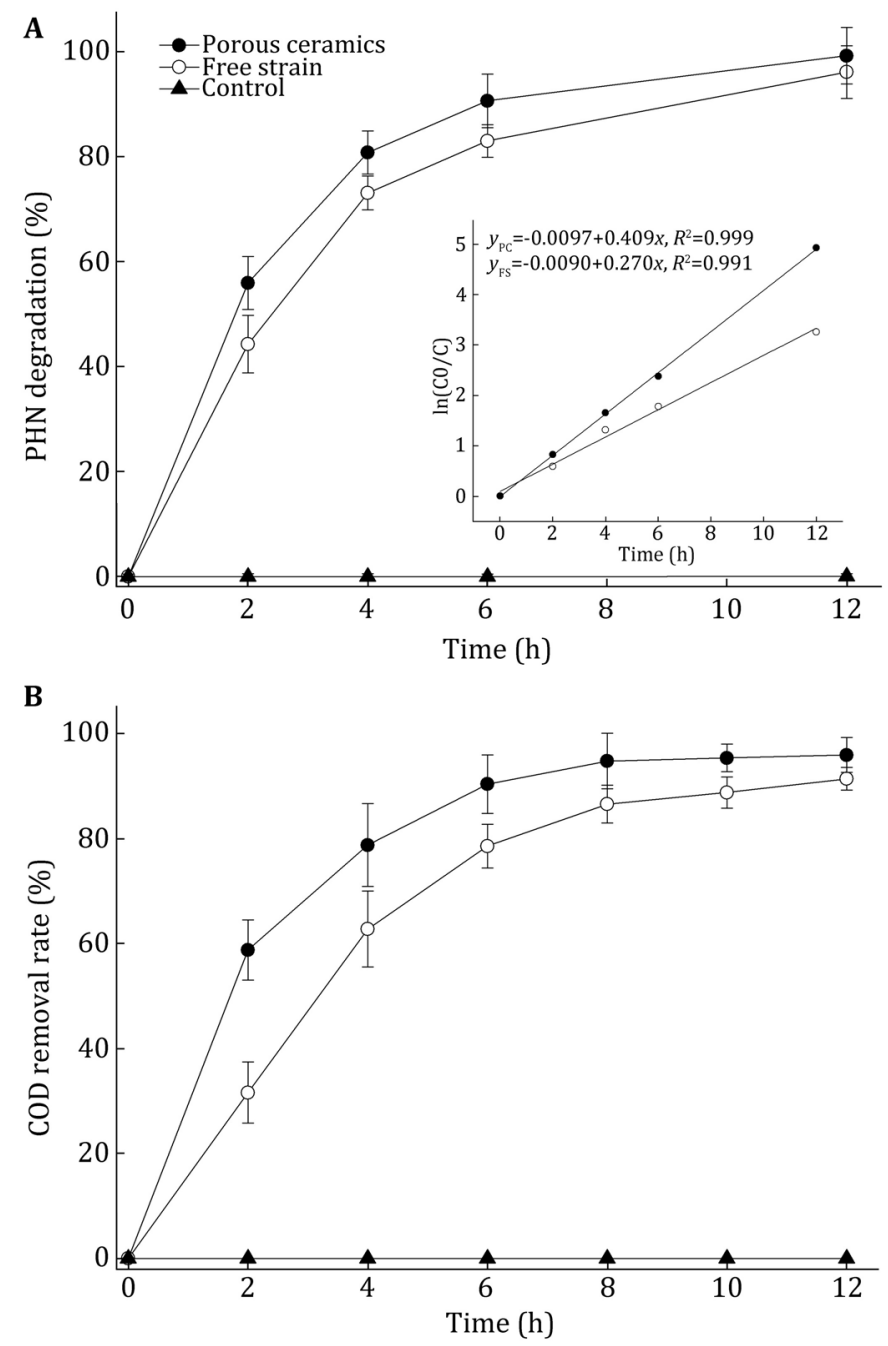
$0.9 \mathrm{mg} / \mathrm{L}$ in $8 \mathrm{~h}$. At the 12th hour of the second phase, the COD removal rate of $94.4 \%$ and the PHN degradation rate of $95.4 \%$ were achieved. In the final phase, the COD removal rate reached $94.3 \%$ at the 12 th hour, and concentration of PHN dropped to $0.7 \mathrm{mg} / \mathrm{L}$ with the degradation rate of $96.5 \%$ at the 16th hour. Effluent concentrations of COD and PHN were maintained around 30 and $0.8 \mathrm{mg} / \mathrm{L}$ in all three phases (Fig. 6). The MBRs used in this study operated stably for 60 days and degradation ability showed no signs of decreasing.

Membrane bioreactor is a good system to treat industrial wastewater (Melin et al. 2006). It has been reported that MBR could remove more than 94\%-98\% COD and TOC (Scholz and Fuchs 2000). Cirja reported removal of organic micropollutants by microorganism in
MBR (Cirja et al. 2008). Streptomyces sp. QWE-35 degraded $200 \mathrm{mg} / \mathrm{L}$ naphthalene in a MBR and could be a potential candidate for coal gasification wastewater treatment (Xu et al. 2014). However, in industrial operations of MBR, using free strain to treat wastewater is not efficient, as free strains are hard to separate from aqueous solution and cause membrane fouling (Zhang et al. 2011). Membrane fouling still limits the widespread application of MBR (Tang et al. 2010). Immobilized microorganism technology is a solution for these disadvantages (Xu et al. 2012). Ceramics is a kind of carrier which can decrease the membrane fouling, enhance the removal rate, harbor the long-term usability in wastewater treatment (Kariminiaae-Hamedaani et al. 2003; Bai et al. 2009). In our study, the system
Fig. 6 Changes in COD and PHN concentrations of the influent and effluent in the MBR with different $\mathrm{pH}$

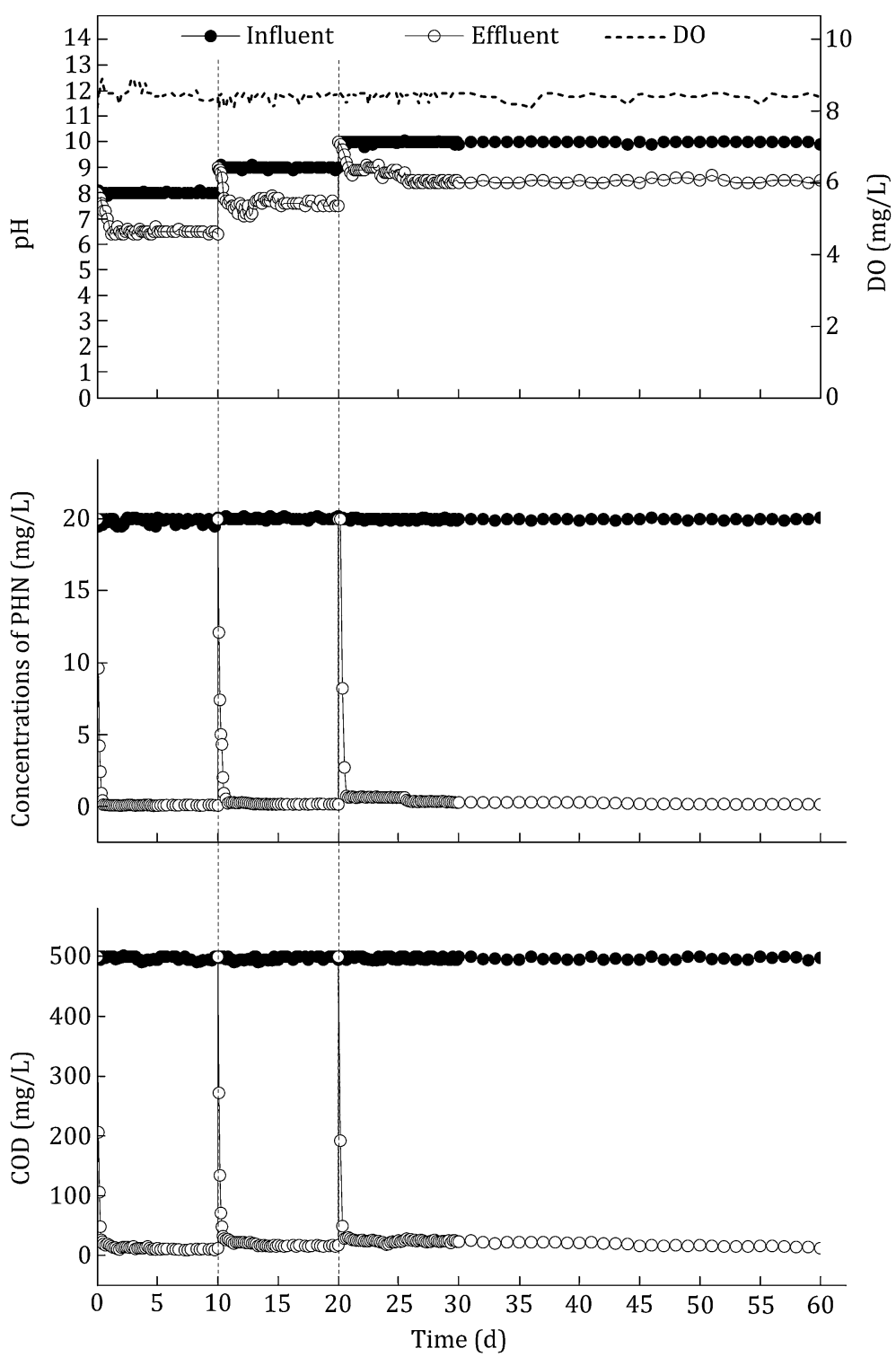


immobilized strain LZ-Q onto ceramic carriers in membrane-bioreactor was able to remove more than $96 \%$ of the influent phenanthrene and $94 \%$ of the influent COD during 60 days of operation when the HRT was $3 \mathrm{~h}$, and degradation ability showed no signs of decreasing.

Hypersaline and hyperalkaline conditions are also limitations of efficiency of wastewater treatment in MBR as biological treatment is strongly inhibited by salts (mainly $\mathrm{NaCl}$ ) (Lefebvre and Moletta 2006). Soltani reported that microorganisms only degraded $50 \%$ PHN in MBR system under high salinity conditions (Soltani et al. 2010). When the salt concentration was up to $84 \mathrm{mg} / \mathrm{L}$, MBR system requires 73 operating days adaptation to recover to the normal COD removal efficiency (Artiga et al. 2008). However, our data indicated that strain LZ-Q could degrade PAHs including phenanthrene efficiently under the hyperhaline and hyperalkaline conditions. The MBR system with immobilized strain LZ-Q operated stably for 60 days without decreasing. All these results suggesting immobilized strain LZ-Q in MBR is a candidate system for degrading phenanthrene in saline-alkali wastewater.

\section{CONCLUSIONS}

An efficient phenanthrene degradation strain LZ-Q, which was isolated from petroleum-contaminated soil in Lanzhou reach of the Yellow River, was identified as $P$. sp. by ViTek 2 and 16S rRNA gene sequencing. The antibiotic-sensitive strain LZ-Q grew in BH medium containing $1 \mathrm{~g} / \mathrm{L}$ phenanthrene as the carbon source and had the ability to degrade phenanthrene with a broad range of salinities (5-75 g/L), pHs (5-10), and temperatures $\left(10-42{ }^{\circ} \mathrm{C}\right)$. Strain LZ-Q degraded phenanthrene efficiently through salicylic acid pathway and phthalic acid pathway. In the $\mathrm{BH} / \mathrm{PHN}$ (100 mg/L) medium, the PHN degradation rate of strain LZ-Q was $92.27 \%$ in 5 days. In addition, strain LZ-Q could use other organic compounds as carbon sources, such as naphthalene, anthracene, pyrene, petrol, and diesel. Compared with free strain, adsorptive ceramic carrier of strain LZ-Q spurs removal rates of COD and PHN from $78.6 \%$ to $90.4 \%$ and $82.04 \%$ to $90.68 \%$ at $6 \mathrm{~h}$. Continuous treatment performance of MBR with immobilized strain LZ-Q operated powerfully and stably in this study. All the observations indicated that MBR with immobilized $P$. sp. LZ-Q could be a candidate to remediate phenanthrene-contaminated saline-alkali sewage.

\section{MATERIALS AND METHODS}

\section{Sample collection}

Soil sampling was carried out near the sewage outlet of a petrochemical company $\left(36^{\circ} 02^{\prime} \mathrm{N}, 103^{\circ} 61^{\prime} \mathrm{E}\right.$, Lanzhou, China) in Gansu province, which is in upper reach of the Yellow River in April, 2013. The climate of sampling site is a typical temperate and monsoonal continental climate, with an annual mean air temperature of $9.3^{\circ} \mathrm{C}$ and precipitation of $360 \mathrm{~mm}$ (Wu et al. 2011). Samples were collected at depth of $15 \mathrm{~cm}$ at $22{ }^{\circ} \mathrm{C}$ and pH 6.2 . After collection, samples were immediately transferred to the laboratory in sterilized aluminum boxes and stored at $-80^{\circ} \mathrm{C}$.

\section{Reagents and culture media}

Phenanthrene, salicylic acid, catechol, phthalic acid, and methyl alcohol were HLC grade, and all the other chemicals were of analytical grade.

Bushnell-Hass mineral salt medium (BH) was composed of (g/L) NaCl 5, $\mathrm{KH}_{2} \mathrm{PO}_{4} 1, \mathrm{~K}_{2} \mathrm{HPO}_{4} 1, \mathrm{NH}_{4} \mathrm{NO}_{3} 1$, $\mathrm{MgSO}_{4} \cdot 7 \mathrm{H}_{2} \mathrm{O} \quad 0.2, \mathrm{CaCl}_{2} \cdot 2 \mathrm{H}_{2} \mathrm{O} \quad 0.02$, and $\mathrm{FeCl}_{3} 0.05$. Luria-Bertani (LB) medium was composed of $(\mathrm{g} / \mathrm{L})$ peptone $10, \mathrm{NaCl} 5$, and yeast extract 10 . Per liter solid LB contained $15 \mathrm{~g}$ agar powder. One liter of synthetic wastewater (SW) consisted of $\mathrm{NaCl} 35 \mathrm{~g}$, glucose $450 \mathrm{mg}, \quad \mathrm{FeCl}_{2} \cdot 4 \mathrm{H}_{2} \mathrm{O} 200 \mathrm{mg}, \mathrm{CaCl}_{2} \cdot 2 \mathrm{H}_{2} \mathrm{O} 200 \mathrm{mg}$, $\mathrm{MgCl}_{2} \cdot 6 \mathrm{H}_{2} \mathrm{O} 300 \mathrm{mg}, \mathrm{CuCl}_{2} \cdot 2 \mathrm{H}_{2} \mathrm{O} 0.6 \mathrm{mg}, \mathrm{ZnCl}_{2} 1 \mathrm{mg}$, $\mathrm{H}_{3} \mathrm{BO}_{3} 1 \mathrm{mg}, \mathrm{MnCl}_{2} \cdot 4 \mathrm{H}_{2} \mathrm{O} 10 \mathrm{mg}, \mathrm{CoCl}_{2} \cdot 6 \mathrm{H}_{2} \mathrm{O} 1 \mathrm{mg}$, $\mathrm{NaMoO}_{4} \cdot 2 \mathrm{H}_{2} \mathrm{O} 0.2 \mathrm{mg}, \mathrm{NiCl}_{2} \cdot 6 \mathrm{H}_{2} \mathrm{O} 1 \mathrm{mg} . \mathrm{NH}_{4} \mathrm{Cl}$, and $\mathrm{K}_{2} \mathrm{HPO}_{4}$ were added into the SW to maintain COD:N:P ratio of 200:5:1. The pH of the SW was adjusted with $25 \mathrm{~g} / \mathrm{L} \mathrm{NaHCO}_{3}$. All prepared media were autoclaved at $121{ }^{\circ} \mathrm{C}$ for $20 \mathrm{~min}$.

\section{Enrichment and isolation of phenanthrene- degrading strain}

Phenanthrene-degrading strains were isolated from the mixed soil samples taken from Lanzhou reach of Yellow River. $1 \mathrm{~g}$ soil was added into $100 \mathrm{~mL} \mathrm{BH}$ supplied with $50 \mathrm{mg}$ phenanthrene as sole carbon and energy source. Enrichments were incubated at $28{ }^{\circ} \mathrm{C}$ and $180 \mathrm{r} / \mathrm{min}$. After 5 days, $1 \mathrm{~mL}$ of enriched aqueous culture was transferred to another $\mathrm{BH} /$ phenanthrene $(500 \mathrm{mg} / \mathrm{L})$ medium. Consecutive enrichment processes were repeated three times for every 5 days until microbial consortium was developed in the medium. Then, $100 \mu \mathrm{L}$ dilute aqueous culture was spread on the solid BH plate. After 2 days, developed colonies on the plates were 
isolated and inoculated into the $\mathrm{BH} /$ phenanthrene medium to confirm their potential of degrading phenanthrene. Repeated plate streaking was employed to ensure purity of the isolates. A mixture of the bacterial solution and $50 \%$ glycerol with a ratio of $1: 1$ $(v / v)$ were stored at $-20^{\circ} \mathrm{C}$.

\section{Characterization and identification of microorganism}

The isolated bacteria were examined using observation of morphological features. Gram staining was performed before biochemical tests were done with the Vitek 2 System (bioMerieux Industry, Marcyl'Etoile, France) according to the manufacturer's instructions.

Molecular identification was carried out by phylogenetic analysis following the 16S rRNA sequencing. The strain was first activated in $5 \mathrm{~mL}$ LB on a shaker at $30^{\circ} \mathrm{C}$ and $180 \mathrm{r} / \mathrm{min}$ for $12 \mathrm{~h}$. Amplification of gene fragments encoding 16S rRNA was performed using the universal 16S rRNA primers (E. coli $27 \mathrm{~F}$ and 1492R). Fragments sequencing was done by Shanghai Majorbio Bio-pharm Technology Co. Ltd (Shanghai, China) and sequences were analyzed at EzTaxon (www.eztaxon.org/) database. Phylogenetic tree was generated by MEGA (Tamura et al. 2007).

\section{Determination of growth characterization and degradation ability}

\section{Growth on phenanthrene}

The optimum temperature test was carried out under the temperatures of $10,28,37$, and $42{ }^{\circ} \mathrm{C}$. Optimum $\mathrm{pH}$ was tested at $\mathrm{pH} 5,6,7,8,9$, and 10. Growth curves were determined by measuring $O D_{600 \mathrm{~nm}}$ in the medium using a spectrophotometer. The isolated strain was separately inoculated into the $100 \mathrm{~mL}$ sterilized $\mathrm{BH}$ medium with $100 \mathrm{mg} / \mathrm{L}$ phenanthrene as sole carbon and cultivated at $\mathrm{pH} 7,180 \mathrm{r} / \mathrm{min}$, and $28^{\circ} \mathrm{C}$. Escherichia coli was used as negative control.

\section{Growth on other carbon sources}

Growth of the pure culture on other carbon substrates, including naphthalene, anthracene, pyrene, salicylic acid, phthalic acid, diphenylamine, petrol, and diesel was tested to find out the potential degradable substrate as sole carbon and energy source. All experiments were in triplicate.

\section{Degradation of phenanthrene}

$1 \mathrm{~mL}$ aliquots of isolated strain were added into $100 \mathrm{~mL}$ sterilized BH medium containing $100 \mathrm{mg} / \mathrm{L}$ phenanthrene for 5 days. Quantity of phenanthrene concentrations and varieties of catabolic intermediates were determined using HPLC. Bacterial solutions were filtered through disposable filters $(0.45 \mu \mathrm{m})$. Phenanthrene and putative metabolites were separated with a silica C18 column $(4.6 \times 150 \mathrm{~mm})$. The mobile phase consisted of $80 \%$ methanol and $20 \%$ water at a flow rate of $1 \mathrm{~mL} / \mathrm{min}$ and room temperature. Eluants were monitored by UV-Vis light detection at a wavelength of $254 \mathrm{~nm}$ and qualified using an external standard calibration curve.

\section{Tolerance of salinity and antibiotics}

Salinity tolerance of the isolate was assayed on BH/PHN(100 mg/L) liquid containing 5, 35, 40, 50, 75, and $100 \mathrm{~g} / \mathrm{L} \mathrm{NaCl}$. The $O D_{600 \mathrm{~nm}}$ was reported in $120 \mathrm{~h}$ of incubation. Antibiotic sensitivity tests were carried out by the Kirby-Bauer antibiotic susceptibility disk diffusion method (Kirby et al. 1966). All experiments were in triplicate.

\section{Bacteria immobilization and reactor setup}

Ceramic-microorganism adsorptive carriers were spherical in shape with the diameter of $2-3 \mathrm{~mm}$, and were prepared as follows: washing with water for three times, and then immersed in $5 \% \mathrm{HCl}$, neutral water, and $5 \% \mathrm{NaOH}$ for $2 \mathrm{~h}$ successively. $100 \mathrm{~mL}$ modified ceramics was placed into $500-\mathrm{mL}$ flasks containing $200 \mathrm{~mL}$ bacterial culture for 3 days with changing LB liquid medium every $24 \mathrm{~h}$. The obtained carriers were washed with normal saline and stored in physiological saline at $4{ }^{\circ} \mathrm{C}$ before using.

This research was carried out in continuous aerating MBRs with $2 \mathrm{~L}$ ( $3 \mathrm{~L}$ of total volume) (Fig. 7). The MBRs operated with micro-filtration (MF) flat-sheet (FS) membrane module with nominal porosity of $0.4 \mu \mathrm{m}$. Free-bacteria or immobilized microorganism carriers were added into reactors. All the other operating conditions for reactors were kept the same. MBRs were operated at $19-21{ }^{\circ} \mathrm{C}$ and were run at 8-12 mg/L DO with the help of an aeration pump. Hydraulic retention time (HRT) was $3 \mathrm{~h}$. The experiment lasted for 60 days and each reactor was set up in triplicate. 


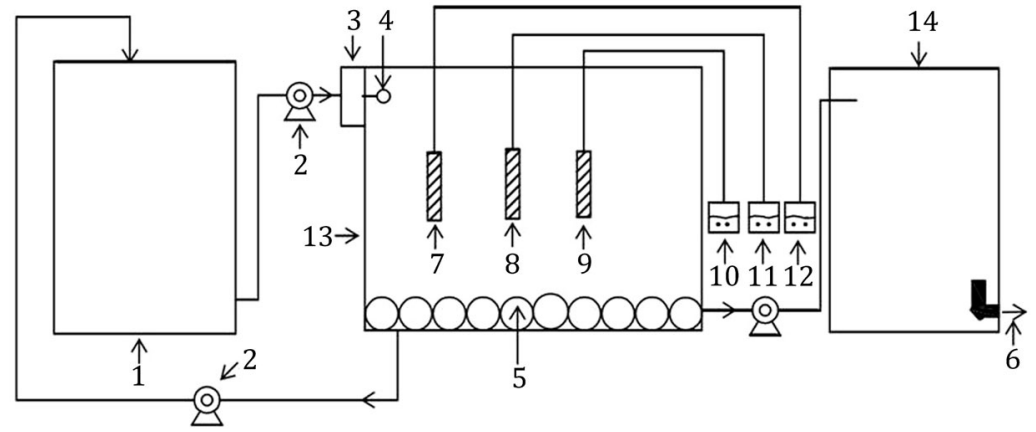

Fig. 7 Simplified scheme of the immobilized microorganisms reactor. 1. Sewage storage tank; 2. Suction pump; 3. Rotameter; 4. Inlet; 5. Aerator; 6. Outlet; 7. DO sensor; 8. Temperature sensor; 9. pH sensor; 10. pH monitor; 11. Temperature monitor; 12 . D0 monitor; 13. Aeration tank; 14. Membrane reactor

\section{Morphological observations}

Morphological observation of scanning electron microscopy (SEM) was done with Hitachi S-3400 N Scanning Electron Microscope (Hitachi High-Technologies Corporation, Tokyo, Japan). Sample preparation for SEM was carried out according to the methods reported before (Zhou et al. 2009).

\section{Chemical analysis}

The chemical oxygen demand $\left(\mathrm{COD}_{\mathrm{Cr}}\right)$ was determined by the standard method based on potassium dichromate $\left(\mathrm{K}_{2} \mathrm{Cr}_{2} \mathrm{O}_{7}\right)$ oxidization method (Zhou et al. 2009).

Acknowledgments This study was supported by National Natural Science Foundation of China (31470224 and 31200085); MOST international cooperation grant (2014DFA91340) and Gansu Provincial International Cooperation (134WCGA176).

\section{Compliance with Ethical Standards}

Conflict of Interest Yiming Jiang, Haiying Huang, Mengru Wu, Xuan Yu, Yong Chen, Pu Liu, and Xiangkai Li declare that they have no conflict of interest.

Human and Animal Rights and Informed Consent This article does not contain any studies with human or animal subjects performed by any of the authors.

Open Access This article is distributed under the terms of the Creative Commons Attribution 4.0 International License (http://creativecommons.org/licenses/by/4.0/), which permits unrestricted use, distribution, and reproduction in any medium, provided you give appropriate credit to the original author(s) and the source, provide a link to the Creative Commons license, and indicate if changes were made.

\section{References}

Artiga P, García-Toriello G, Méndez R, Garrido J (2008) Use of a hybrid membrane bioreactor for the treatment of saline wastewater from a fish canning factory. Desalination 221:518-525

Bai X, Ye Z, Qu Y, Li Y, Wang Z (2009) Immobilization of nanoscale Fe-0 in and on PVA microspheres for nitrobenzene reduction. J Hazard Mater 172:1357-1364

Bamforth SM, Singleton I (2005) Bioremediation of polycyclic aromatic hydrocarbons: current knowledge and future directions. J Chem Technol Biotechnol 80:723-736

Boldrin B, Tiehm A, Fritzsche C (1993) Degradation of phenanthrene, fluorene, fluoranthene, and pyrene by a Mycobacterium sp. Appl Environ Microbiol 59:1927-1930

Chowdhury PP, Sarkar J, Basu S, Dutta TK (2014) Metabolism of 2-hydroxy-1-naphthoic acid and naphthalene via gentisic acid by distinctly different sets of enzymes in Burkholderia sp. strain BC1. Microbiology 160:892-902

Cirja M, Ivashechkin P, Schäffer A, Corvini PF (2008) Factors affecting the removal of organic micropollutants from wastewater in conventional treatment plants (CTP) and membrane bioreactors (MBR). Rev Environ Sci Bio/Technol 7:61-78

González D, Ruiz LM, Garralón G, Plaza F, Arévalo J, Parada J, Pérez J, Moreno B, Gómez MÁ (2012) Wastewater polycyclic aromatic hydrocarbons removal by membrane bioreactor. Desalination Water Treat 42:94-99

Haritash A, Kaushik C (2009) Biodegradation aspects of polycyclic aromatic hydrocarbons (PAHs): a review. J Hazard Mater 169:1-15

Janbandhu A, Fulekar M (2011) Biodegradation of phenanthrene using adapted microbial consortium isolated from petrochemical contaminated environment. J Hazard Mater 187:333-340

Jerina DM, Yagi H, Lehr RE, Thakker DR, Schaefer-Ridder M, Karle JM, Levin W, Wood AW, Chang RL, Conney AH (2012) The bayregion theory of carcinogenesis by polycyclic aromatic hydrocarbons. Polycycl Hydrocarb Cancer 1:173-188

Jia Y, Yin H, Ye JS, Peng H, He BY, Qin HM, Zhang N, Qiang J (2008) Characteristics and pathway of naphthalene degradation by Pseudomonas sp. N7. Environ Sci 29:756-762

Juang R, Chung T, Wang M, Lee D (2008) Experimental observations on the effect of added dispersing agent on phenol biodegradation in a microporous membrane bioreactor. J Hazard Mater 151:746-752

Kariminiaae-Hamedaani H-R, Kanda K, Kato F (2003) Wastewater treatment with bacteria immobilized onto a ceramic carrier in an aerated system. J Biosci Bioeng 95:128-132

Kirby WM, Baner AW, Sherris KC, Truck M (1966) Antibiotic susceptibility testing by a standard single disc method. Am J Clin Pathol 45:493-502 
Kunst F, Rapoport G (1995) Salt stress is an environmental signal affecting degradative enzyme synthesis in Bacillus subtilis. J Bacteriol 177:2403-2407

Lefebvre 0, Moletta R (2006) Treatment of organic pollution in industrial saline wastewater: a literature review. Water Res 40:3671-3682

Lin M, Hu X, Chen W, Wang H, Wang C (2014) Biodegradation of phenanthrene by Pseudomonas sp. BZ-3, isolated from crude oil contaminated soil. Int Biodeterior Biodegrad 94:176-181

Ma C, Wang Y, Zhuang L, Huang D, Zhou S, Li F (2011) Anaerobic degradation of phenanthrene by a newly isolated humusreducing bacterium, Pseudomonas aeruginosa strain PAH-1. J Soils Sediments 11:923-929

Ma J, Xu L, Jia L (2012) Degradation of polycyclic aromatic hydrocarbons by Pseudomonas sp. JM2 isolated from active sewage sludge of chemical plant. J Environ Sci 24:2141-2148

Masakorala K, Yao J, Cai M, Chandankere R, Yuan H, Chen H (2013) Isolation and characterization of a novel phenanthrene (PHE) degrading strain Psuedomonas sp. USTB-RU from petroleum contaminated soil. J Hazard Mater 263:493-500

Melin T, Jefferson B, Bixio D, Thoeye C, De Wilde W, De Koning J, van der Graaf J, Wintgens T (2006) Membrane bioreactor technology for wastewater treatment and reuse. Desalination 187:271-282

Metcalf E (2003) Wastewater engineering, treatment and reuse. McGraw-Hill, New York

Nagadomi H, Kitamura T, Watanabe M, Sasaki K (2000) Simultaneous removal of chemical oxygen demand (COD), phosphate, nitrate and $\mathrm{H}_{2} \mathrm{~S}$ in the synthetic sewage wastewater using porous ceramic immobilized photosynthetic bacteria. Biotechnol Lett 22:1369-1374

Parameswarappa S, Karigar C, Nagenahalli M (2008) Degradation of ethylbenzene by free and immobilized Pseudomonas fluorescens-CS2. Biodegradation 19:137-144

Park D, Lee DS, Joung JY, Park JM (2005) Comparison of different bioreactor systems for indirect $\mathrm{H}_{2} \mathrm{~S}$ removal using ironoxidizing bacteria. Process Biochem 40:1461-1467

Patel V, Cheturvedula S, Madamwar D (2012) Phenanthrene degradation by Pseudoxanthomonas sp. DMVP2 isolated from hydrocarbon contaminated sediment of Amlakhadi canal, Gujarat, India. J Hazard Mater 201:43-51

Peng RH, Xiong AS, Xue Y, Fu XY, Gao F, Zhao W, Tian YS, Yao QH (2008) Microbial biodegradation of polyaromatic hydrocarbons. FEMS Microbiol Rev 32:927-955

Prabhu Y, Phale P (2003) Biodegradation of phenanthrene by Pseudomonas sp. strain PP2: novel metabolic pathway, role of biosurfactant and cell surface hydrophobicity in hydrocarbon assimilation. Appl Microbiol Biotechnol 61:342-351

Scholz W, Fuchs W (2000) Treatment of oil contaminated wastewater in a membrane bioreactor. Water Res 34:3621-3629

Schwarzenbach RP, Egli T, Hofstetter TB, Von Gunten U, Wehrli B (2010) Global water pollution and human health. Annu Rev Environ Resour 35:109-136

Soltani S, Mowla D, Vossoughi M, Hesampour M (2010) Experimental investigation of oily water treatment by membrane bioreactor. Desalination 250:598-600
Sun K, Liu J, Gao Y, Jin L, Gu Y, Wang W (2014) Isolation, plant colonization potential, and phenanthrene degradation performance of the endophytic bacterium Pseudomonas sp. Ph6-gfp Scientific reports 4

Tamura K, Dudley J, Nei M, Kumar S (2007) MEGA4: molecular evolutionary genetics analysis (MEGA) software version 4.0. Mol Biol Evol 24:1596-1599

Tang S, Wang Z, Wu Z, Zhou Q (2010) Role of dissolved organic matters (DOM) in membrane fouling of membrane bioreactors for municipal wastewater treatment. J Hazard Mater 178:377-384

Ting YP, Sun G (2000) Use of polyvinyl alcohol as a cell immobilization matrix for copper biosorption by yeast cells. J Chem Technol Biotechnol 75:541-546

Wang X-T, Miao Y, Zhang Y, Li Y-C, Wu M-H, Yu G (2013) Polycyclic aromatic hydrocarbons (PAHs) in urban soils of the megacity Shanghai: occurrence, source apportionment and potential human health risk. Sci Total Environ 447:80-89

Wu M, Nie M, Wang X, Su J, Cao W (2010) Analysis of phenanthrene biodegradation by using FTIR, UV and GCMS. Spectrochim Acta, Part A 75:1047-1050

Wu SM, Huang SY, Fu BQ Liu GY, Chen JX, Chen MX, Yuan ZG, Zhou DH, Weng YB, Zhu XQ Ye DH (2011) Seroprevalence of Toxoplasma gondii infection in pet dogs in Lanzhou, Northwest China. Parasit Vectors 4:64

Xu P, Zeng GM, Huang DL, Feng CL, Hu S, Zhao MH, Lai C, Wei Z, Huang C, Xie GX, Liu ZF (2012) Use of iron oxide nanomaterials in wastewater treatment: a review. Sci Total Environ 424:1-10

Xu P, Ma W, Han H, Jia S, Hou B (2014) Isolation of a naphthalenedegrading strain from activated sludge and bioaugmentation with it in a MBR treating coal gasification wastewater. Bull Environ Contam Toxicol 94:1-7

Yan G, Viraraghavan T (2001) Heavy metal removal in a biosorption column by immobilized $M$. rouxii biomass. Bioresour Technol 78:243-249

Yang Y, Chen RF, Shiaris MP (1994) Metabolism of naphthalene, fluorene, and phenanthrene: preliminary characterization of a cloned gene cluster from Pseudomonas putida NCIB 9816. J Bacteriol 176:2158-2164

Zhang D, Zeng X, Li W, He H, Ma P, Falandysz J (2011) Selection of optimum formulation for biosorbing lead and cadmium from aquatic solution by using PVA-SA's immobilizing Lentinus edodes residue. Desalination Water Treat 31:107114

Zhao H-P, Wu Q-S, Wang L, Zhao X-T, Gao H-W (2009) Degradation of phenanthrene by bacterial strain isolated from soil in oil refinery fields in Shanghai China. J Hazard Mater 164: 863-869

Zhou L, Bai X, Li Y, Ma P (2008) Immobilization of micro-organism on macroporous polyurethane carriers. Environ Eng Sci 25:1235-1242

Zhou L, Li Y, Bai X, Zhao G (2009) Use of microorganisms immobilized on composite polyurethane foam to remove $\mathrm{Cu}$ (II) from aqueous solution. J Hazard Mater 167:11061113 